\title{
Home environmental problems and physical function in Taiwanese older adults
}

\author{
Tzuo-Yun Lan ${ }^{\mathrm{a}, *}$, Shwu-Chong Wu ${ }^{\mathrm{b}}$, Wen-Chiung Chang ${ }^{\mathrm{a}}$, Ching-Yu Chen ${ }^{\mathrm{a}}$ \\ a Division of Gerontology Research, National Health Research Institutes, 35, Keyan Road, Zhunan Town, Miaoli County 350, Taiwan \\ ${ }^{\mathrm{b}}$ Institute of Health Policy and Management, College of Public Health, National Taiwan University, 17, Xu-Zhou Road, Taipei 100, Taiwan
}

\section{A R T I C L E I N F O}

\section{Article history:}

Received 27 May 2008

Received in revised form 21 November 2008

Accepted 25 November 2008

Available online 4 January 2009

\section{Keywords:}

Environmental hazards

Physical function

Elderly

Taiwan

\begin{abstract}
A B S T R A C T
Environmental hazards play an important role in the disablement process. The purpose of this study was to investigate the relationship between home environmental problems and personal physical function. Data were based on a two-stage nationwide survey and evaluation on the needs of long-term care in Taiwan. A total of 10,596 individuals aged 65 and over were included in this study. These participants were identified with physical or cognitive problems at the screening interview and further evaluated at the second interview on health condition, functional status, needs of long-term care, and home environmental problems. Six items of environmental hazards were assessed at the participants' homes with direct observation. The prevalence rates of home environmental problems were similar among older adults with different levels of physical function. No grab bars (79.6-85.1\%) and no protections against slip (81.9-92.8\%) in the bathroom were two commonly present hazards in older adults' homes. Older adults with a higher income (Odds ratio $=\mathrm{OR}=0.75$ ), without income information $(\mathrm{OR}=0.78)$ or living with other persons $(\mathrm{OR}=0.74)$ were less likely to experience environmental problems at home. Results from this study revealed that home environment condition was associated with factors other than personal disabling conditions for the elderly. Modifying home environment, especially the bathroom, should be attached with great importance for physically disabled older adults.
\end{abstract}

(c) 2008 Elsevier Ireland Ltd. All rights reserved.

\section{Introduction}

Understanding environmental factors that interact with the main components in the disablement process (Verbrugge and Jette, 1997; WHO, 2001) is important to prevent or postpone disability and subsequent adverse outcomes, such as falls and death. Currently, few small-scale studies have shown that older disabled persons were no less likely, or even more likely, to experience home environmental problems than their non-disabled counterparts (Gill et al., 1999a,b). Further analysis based on a larger-scale and more representative population-based survey can be expected to provide an opportunity to examine previous findings and to help in characterizing the relationship between home environment and physical function. In this study, we aimed to assess the conditions of home environment among older adults with different levels of physical function, and to identify the association between home environmental hazards and functional status, adjusted with demographic, social, and health factors.

\footnotetext{
* Corresponding author. Tel.: +886 37246 166; fax: +886 37586261

E-mail address: tylan@nhri.org.tw (T.-Y. Lan).
}

\section{Materials and methods}

\subsection{Study participants}

This study analyzed data from a nationwide survey on the needs of long-term care in Taiwan in 2002. Methods and study design of the survey have been described in detail elsewhere (Department of Health, 2002). In brief, to obtain a representative sample, townships and nearby areas in all 23 counties and cities in Taiwan were served as the basic sampling units. Sample size for each sampling unit was determined by the relative proportion of older adults and the physician density. All samples were selected using the method of probability proportional to size. A total of 303,545 community dwellers aged 50 and over was finally selected by multistage sampling method from 204 sampling townships and districts nationwide. All 239,861 (79.0\%) participants who agreed to join the survey underwent a baseline interview including 7 items of the activities of daily living (ADL) (Katz et al., 1963), 8 items of the instrumental activities of daily living (IADL) (Lawton and Brody, 1969), and 10 items for assessing cognitive function (Pfeiffer, 1975). All the screening questionnaires were examined by public health nurses to identify those with potential functional problems. Those who reported using assistive device, were in need of other's help or unable to do at least one ADLs task, having difficulty in 
doing at least five IADLs tasks, or giving at least six wrong answers in the cognitive assessment during the screening interview were further evaluated to learn about their long-term care needs and other health-related information in the re-interview approximately 6 months later. The criteria were decided by a multidisciplinary working group. Of the 17,191 (7.2\%) participants identified with potential functional problems in the screening interview, 1395 died, 451 moved, 132 were unable to be contacted, 488 declined further participation, and 100 were too frail or hospitalized, leaving our study a total of 14,625 (85.1\%) participants in the second interview. Conducted at the participants' homes by train nurses, the second interview included a wide range of intensive assessment covering health status, physical and sensory function, social and family support, mental health, use of medical and long-term care, nursing and rehabilitation needs, and home environmental hazards. Since this study aimed to understand the relationship between home environment and physical function of community-dwelling older people, those who were institutionalized at the time of interviews (1346), who were screened with functional problems but were non-disabled in the second interview (531), or whose age was less than 65 (2152) were excluded. Ultimately 10,596 participants were left for further analysis in this study.

\subsection{Functional status}

Functional status was determined by ADLs (including eating, getting in and out of bed, standing from and sitting on a chair, walking in a room, dressing, bathing, and toileting) and IADLs questions (including light housework, laundry, cooking, walking outside, shopping, managing money, taking medicines, and making a phone call). We employed similar approach adopted by Ferrucci et al. (1997) to classify the physical disability level into four groups. Participants with no difficulty in doing both ADLs and IADLs tasks were classified as no disability. Participants who reported difficulty in at least one IADLs task were classified as mild disability. Participants who reported inability, using assistive devices, or needing other's assistance in doing one or two ADLs tasks and in doing three or more ADL tasks were classified respectively as moderate disability and severe disability.

\subsection{Home environmental problems}

Based mainly on their potential in causing falls or inconvenience for disabled older persons in the household environment in Taiwan, 6 items used for the survey were selected from a variety of commonly seen home hazard items that are used in existing assessment tools of long-term care. These consist difficulties on access to entrance of the building (including no elevator for a building with two and more floors, high threshold, no barrier-free entryway, or no handrail for stairs), limited space or narrow entryway in the bathroom, no protections such as non-skid mat against slip in the bathroom, no grab bars in the tub or shower, limited space or narrow entryway in the main bedroom, and poor indoor lightening condition. Each of the 6 items was objectively ascertained by the interviewers as "no problem observed" or "problem observed". To standardize the assessment, all interviewers were given a one-hour training course on home environmental evaluation by an experienced occupational therapist in the two-day training program prior to conducting the interviews. The prevalence of home environment problems among older adults with different levels of physical function was weighted to facilitate estimates representative of the community-living older (aged 65 and over) population in Taiwan. Total problems were also computed and further categorized in the multiple logistic regression analysis as low (0-2 problems) or high ( 3 and more problems) hazardous household environment.

\subsection{Other background information}

Health condition was measured with 10 common chronic conditions in the elderly told by doctor, namely, hypertension, heart disease, diabetes, stroke, psychiatric disorder, Parkinson's disease/Parkinsonism, cancer, arthritis, and respiratory disease. Total number of chronic conditions was calculated and grouped into $0,1,2,3$ and more. Living arrangement was categorized as either living alone or living with others. Average personal income, based on total monthly household income divided by total number of family members, was used as the indicator of income and categorized as low (less than NT\$ 5000), middle (between NT\$ 5000 and NT\$10,000), and high (over NT\$10,000). Participants who did not provide income information were coded as "missing" in the variable of "income".

\section{Results}

Of the 10,596 participants analyzed, $62.4 \%$ were women, and the mean age was $78.1 \pm 7.5$ ( \pm S.D.). Over half (51.5\%) of the participants were classified as with severe disability. The proportions for persons with moderate, mild, and no disability were $19.5 \%, 14.6 \%$, and $14.4 \%$ respectively. Most participants (92.6\%) were not living alone. The average number of chronic conditions was $1.8 \pm 1.4$. The average personal income was low for $28.1 \%$ of the participants, middle for $21.0 \%$, high for $20.6 \%$, and missing for $30.3 \%$. Over one-third (36.2\%) of the participants' homes were found to have two environmental problems, and $20 \%$ of the participants' homes had three environmental problems. Four and more environmental problems were found in $33.3 \%$ of the participants' homes while only $10.3 \%$ of the participants' homes had one or no environmental problem. The average number of home environmental problems was $3.0 \pm 1.5$.

Table 1 shows the prevalence of home environmental problems among participants with different physical disability levels. Of the

Table 1

Prevalence and 95\% confidence interval (CI) of six home environmental problems among older adults with different level of physical disability.

\begin{tabular}{|c|c|c|c|c|c|}
\hline \multirow[t]{2}{*}{ Home problems/prevalence $\%$ a $(95 \% \mathrm{CI}$ ) } & \multicolumn{4}{|l|}{ Disability level } & \multirow[t]{2}{*}{$p^{b}$} \\
\hline & No $(n=1518)$ & Mild $(n=1545)$ & Moderate $(n=2061)$ & Severe $(n=5415)$ & \\
\hline Poor access to the entrance of the building & $43.0(40.2-45.9)$ & $47.2(44.4-50.0)$ & $46.7(44.3-49.1)$ & $49.2(47.7-50.7)$ & 0.003 \\
\hline Limited entryway or space in the bathroom & $35.5(32.7-38.3)$ & $41.9(39.1-44.6)$ & $38.3(35.9-40.6)$ & $42.6(41.1-44.1)$ & $<0.001$ \\
\hline No grab bars in the tub or shower & $85.1(83.1-87.2)$ & $84.8(82.7-86.8)$ & $81.6(79.8-83.5)$ & $79.6(78.4-80.8)$ & $<0.001$ \\
\hline No protections against slip in the bathroom & $92.8(91.3-94.3)$ & $89.5(87.8-91.2)$ & $86.1(84.5-87.8)$ & $81.9(80.8-83.1)$ & $<0.001$ \\
\hline Limited entryway or small space in the bedroom & $29.6(27.0-32.3)$ & $31.5(28.9-34.1)$ & $28.6(26.5-30.8)$ & $29.1(27.7-30.4)$ & 0.342 \\
\hline Poor indoor lightening condition & $17.9(15.7-20.2)$ & $17.7(15.6-19.9)$ & $15.8(14.1-17.6)$ & $16.8(15.7-17.9)$ & 0.455 \\
\hline Total problems & $3.04(2.96-3.12)$ & $3.12(3.04-3.21)$ & $2.97(2.90-3.04)$ & $2.99(2.95-3.03)$ & 0.019 \\
\hline
\end{tabular}

\footnotetext{
a Rates were all weighted to represent the total population.

b $p$-Values were calculated with analysis of variance (ANOVA).
} 
six home environmental problems, absence of grab bars and protections against slip in the bathroom were two of the most prevalent home hazards, ranging respectively from $79.6 \%$ to $85.1 \%$ and $81.9 \%$ to $92.8 \%$ across older adults with different levels of physical function. The remaining four problems, on the other hand, were relatively uncommon; indoor lighting condition (ranging from $15.8 \%$ to $17.9 \%$ ) in particular was not a problem in the majority of household environment. Statistically significant differences $(p<0.001)$ of prevalence rates among different physical disability levels were found for limited space or narrow entryway in the bathroom, no protections against slip in the bathroom, and no grab bars in the tub or shower, in which more disabled persons had higher rate for the first problem but lower rates for the latter two problems. Overall, older, physically disabled community dwellers were not statistically different from their non-disabled counterparts in the home environment in terms of the total number of home environmental problems (ranging 2.99-3.12).

Because at least two problems (such as no grab bars and no protections in the bathroom) were found in most cases, dichotomized total problems as set out previously were used as the dependent variable in the logistic regression model to examine the relationship between home environmental hazard, physical disability, and other covariates. Table 2 provides the estimated risk of participants with different social and health characteristics to live in a more hazardous home environment. After adjusting for other covariates, there was no significantly higher or lower risk of having more home environmental problems for participants with different levels of physical disability (ORs $=1.09-1.18$ ) as compared to their non-disabled counterparts. However, statistical significance occurred among participants with different living and financial status. Participants who lived alone had relatively higher risk ( $O R=1.35$ ) while those having high income $(O R=0.75)$ or leaving income information blank $(\mathrm{OR}=0.78)$ were less likely to live in a more hazardous home environment.

\section{Discussion}

Similar to previous studies (Carter et al., 1997; Sattin et al., 1998; Gill et al., 1999b), results from this study also found that living at home with multiple environment problems was common for older community older dwellers, and the overall home

Table 2

Odds ratio and $95 \% \mathrm{CI}$ of selected variables in multiple logistic regression model estimating hazardous home environment.

\begin{tabular}{|c|c|c|c|}
\hline Variables & $n(\%)$ & Weighted OR & $95 \% \mathrm{CI}$ \\
\hline \multicolumn{4}{|l|}{ Sex $($ male $=1)$} \\
\hline Female & $6599(62.4)$ & 0.89 & $0.82-0.98$ \\
\hline \multicolumn{4}{|l|}{ Age $(65-74=1)$} \\
\hline $75-84$ & 4619 (43.7) & 1.06 & $0.97-1.17$ \\
\hline 85 and over & $2279(21.6)$ & 1.08 & $0.95-1.22$ \\
\hline \multicolumn{4}{|c|}{ Disability $($ no $=1$ ) } \\
\hline Mild & $1550(14.7)$ & 1.15 & $0.98-1.36$ \\
\hline Moderate & $2067(19.6)$ & 1.09 & $0.93-1.27$ \\
\hline Severe & $5432(51.4)$ & 1.18 & $1.03-1.35$ \\
\hline \multicolumn{4}{|c|}{ Number of chronic conditions (none $=1$ ) } \\
\hline 1 & $2768(26.2)$ & 1.15 & $1.00-1.31$ \\
\hline 2 & $2753(26.0)$ & 1.16 & $1.02-1.33$ \\
\hline 3 and more & $3105(29.4)$ & 1.24 & $1.09-1.42$ \\
\hline \multicolumn{4}{|c|}{ Living arrangement (not alone $=1$ ) } \\
\hline Alone & $777(7.4)$ & 1.35 & $1.13-1.62$ \\
\hline \multicolumn{4}{|c|}{ Income $($ low $=1)$} \\
\hline Middle & $2219(21.0)$ & 0.97 & $0.85-1.10$ \\
\hline High & $2178(20.6)$ & 0.75 & $0.66-0.85^{*}$ \\
\hline Missing & $3202(30.3)$ & 0.78 & $0.70-0.88^{*}$ \\
\hline
\end{tabular}

$p<0.001$. environmental problems were no less prevalent at the homes of physically disabled older adults than they were at the homes of their non-disabled counterparts, even after adjustments were made for individual demographic and health characteristics.

Among the six home environmental problems, no grab bars in the tub or shower and no protection against slip in the bathroom were highly prevalent at the homes of older persons, but were less common for participants with physical disability. This is consistent with the findings in a previous study (Gill et al., 1999a). A possible explanation is that, although bath aids and protections are rarely considered as indispensable in the community (Chamberlain, 1979; Mann et al., 1996), families with disabled older members tend to be more aware of the safety concerns in the bathroom because it is one of the high-risk places where older persons are more likely to experience fall accident.

However, our findings from logistic regression analysis are different from those in another study (Gitlin et al., 2001) using hierarchical multiple regression analysis and suggesting that gender, age, and physical disability were associated with environmental problems, whereas income, health, and living status were not. In our study, only living arrangement and income were significantly related to home environmental problems, with higher income or living with other persons associated with fewer problems. In terms of living status, a possible explanation is that most of the people living alone are usually unaware of the hazards around them; some of them might know these hazards but are unable or unwilling to modify their home environment. For income, persons with a higher income in Taiwan are usually unwilling to report their income. Therefore, older persons with missing information on income in this study were more likely to have higher income and had similar OR of environmental hazard as that of persons with high income. In addition, previous study has suggested that persons who are relatively rich have less financial barrier to modify environmental problems and to make home environment safer (Norburn et al., 1995). The association between income and environmental problems found in this study is therefore not surprising.

Our study sample was the largest one that represented the community-based older population with different levels of physical function in Taiwan. Therefore, the major strength of this study lies in the ability of the obtained home environment information, including estimates of problems present at the homes of older adults with or without reduced physical function and the magnitude of effects from personal factors on these problems, to serve as a baseline for further researches on home environmental problems.

In spite of the strength of this research, several limitations need to be noted. First, there was an interval of 6 months between functional status evaluation and home environment assessment. The potential bias from the different time points of data collection cannot be excluded. Second, only 6 items of potential home problems were included in the study, and there might be some other important items that are hazardous and ought to be included, such as table, chair, or toilet height. However, given an extremely large study sample, it is not practical to assess home environment with a wide range of items. Moreover, all the items were selected by a panel of experts and thought to be a good summary measure of home environment problems concerning the elderly living in Taiwan, although the validity and reliability were yet to be tested. Third, similar to other cross-sectional survey, this study was not able to identify the causal relationship between factors and home environment problems, and the effect on subsequent outcomes resulting from home environment problems such as falls (Northridge et al., 1995; Sattin et al., 1998). Fourth, our home environment assessment was based on objective observation without taking into consideration of self-reported information on personal attitudes toward the home environmental problems. It is, of course, impossible for us to understand the actual interaction 
between individuals and their home environment, which might include personal encounter or avoidance to cope with the potential hazards (Shumway-Cook et al., 2002, 2003).

It is clear that poor home environment is common for older adults not only in well-developed countries like the United States but also in newly developed or developing countries such as Taiwan. To older adults with or without functional problems, poor home environment imposes huge negative impacts on their daily lives. Developing strategies to make home environment safer for older adults is of crucial importance not only for postponing disability occurrence but also for preventing fall accident.

\section{Conflict of interest statement}

None.

\section{Acknowledgments}

This study was supported by grants DOH-90-MA-5L01 \& DOH90-MA-1031 from the Department of Health, Taiwan.

\section{References}

Carter, S.E., Campbell, E.M., Sanson Fisher, R.W., Redman, S., Gillespie, W.J., 1997. Environmental hazards in the homes of older people. Age Ageing 26, 195-202.

Chamberlain, M.A., 1979. Aids and appliances in the home-a critical survey of bath aids and their use. Int. Rehabil. Med. 1, 204-207.

Department of Health, 2002. The Assessment of National Long-Term Care Need in Taiwan. Department of Health, Executive Yuan, Taipei.

Ferrucci, L., Guralnik, J.M., Pahor, M., Corti, M.C., Havlik, R.J., 1997. Hospital diagnoses, medicare charges, and nursing home admissions in the year when older persons become severely disabled. J. Am. Med. Assoc. 277, 728-734.
Gill, T.M., Robison, J.T., Williams, C.S., Tinetti, M.E., 1999a. Mismatches between the home environment and physical capabilities among community-living older persons. J. Am. Geriatr. Soc. 47, 88-92.

Gill, T.M., Williams, C.S., Robison, J.T., Tinetti, M.E., 1999b. A population-based study of environmental hazards in the homes of older persons. Am. J. Public Health 89, 553-556.

Gitlin, L.N., Mann, W., Tomit, M., Marcus, S.M., 2001. Factors associated with home environmental problems among community-living older people. Disabil. Rehabil. 23, 777-787.

Katz, S., Ford, A.B., Moskowitz, R.W., Jackson, B.A., Jaffee, M.W., 1963. Studies of illness in the aged. The index of ADL: a standardized measure of biological and psychosocial function. J. Am. Med. Assoc. 185, 914-919.

Lawton, M.P., Brody, E.M., 1969. Assessment of older people: self-maintaining and instrumental activities of daily living. Gerontologist 9, 179-186.

Mann, W.C., Hurren, D., Tomita, M., Charvat, B., 1996. Use of assistive devices for bathing by elderly who are not institutionalized. Occup. Ther. J. Res. 16, 261-286.

Norburn, J.E., Bernard, S.L., Konrad, T.R., Woomert, A., DeFriese, G.H., Kalsbeek, W.D. Koch, G.G., Ory, M.G., 1995. Self-care and assistance from others in coping with functional status limitations among a national sample of older adults. J. Gerontol. B: Psychol. Sci. Soc. Sci. 50, S101-S109.

Northridge, M.E., Nevitt, M.C., Kelsey, J.L., Link, B., 1995. Home hazards and falls in the elderly: the role of health and functional status. Am. J. Public Health 85 , 509-515.

Pfeiffer, E., 1975. A short portable mental status questionnaire for the assessment of organic brain deficit in elderly patients. J. Am. Geriatr. Soc. 23, 433-441.

Sattin, R.W., Rodriguez, J.G., De Vito, C.A., Wingo, P.A., 1998. Home environmental hazards and the risk of fall injury events among community-dwelling older persons. Study to Assess Falls Among the Elderly (SAFE) Group. J. Am. Geriatr. Soc. 46, 669-676.

Shumway-Cook, A., Patla, A.E., Stewart, A., Ferrucci, L., Ciol, M.A., Guralnik, J.M., 2002. Environmental demands associated with community mobility in older adults with and without mobility disabilities. Phys. Ther. 82, 670-681.

Shumway-Cook, A., Patla, A., Stewart, A., Ferrucci, L., Ciol, M.A., Guralnik, J.M., 2003. Environmental components of mobility disability in community-living older persons. J. Am. Geriatr. Soc. 51, 393-398.

Verbrugge, L.M., Jette, A.M., 1997. The disablement process. Soc. Sci. Med. 38, 1-14.

WHO (World Health Organization), 2001. International Classification of Functioning, Disability and Health (ICF). WHO, Geneva, Switzerland. 